\title{
Overexpression of GRO- $\beta$ is associated with an unfavorable outcome in colorectal cancer
}

\author{
GUIHUA WANG ${ }^{1}$, JIANFEI HUANG ${ }^{2}$, HUIJUN ZHU $^{2}$, SHAOQING JU $^{1}$, HUIMIN WANG $^{1}$ and XUDONG WANG ${ }^{1}$ \\ ${ }^{1}$ Center of Clinical Laboratory Medicine; ${ }^{2}$ Department of Pathology, Affiliated Hospital of Nantong University, \\ Nantong, Jiangsu 226001, P.R. China
}

Received March 1, 2015; Accepted January 18, 2016

DOI: $10.3892 / \mathrm{ol} .2016 .4222$

\begin{abstract}
Growth-related oncogene (GRO)- $\beta$, or chemokine (C-X-C motif) ligand 2 (CXCL2), is a member of the CXC chemokine family that may mediate various functions, including attracting neutrophils to sites of inflammation, and participating in tumorigenesis and progression. However, the expression of GRO- $\beta$ in colorectal cancer (CRC) and the association with the clinical outcome of the disease remains poorly understood. In the present study, CXCL2 mRNA expression in CRC was analyzed using six independent datasets from the Oncomine microarray database. The immunohistochemical analysis of tissue microarrays (TMA) was used to characterize the expression of the GRO- $\beta$ protein in CRC. The association between GRO- $\beta$ expression and the clinicopathological features and prognosis of patients was determined by statistical analysis. The results indicated that GRO- $\beta$ was highly expressed in CRC tissues, and that high GRO- $\beta$ cytoplasmic expression was associated with the tumor location, extent of the primary tumor, and lymph node metastasis. Kaplan-Meier survival and Cox regression analysis revealed that high GRO- $\beta$ expression was an independent indicator of poor prognosis for CRC patients. The results indicate that high GRO- $\beta$ expression in CRC may correlate with an unfavorable outcome and facilitate cancer cell invasion and metastasis.
\end{abstract}

\section{Introduction}

Colorectal cancer (CRC) is the second most commonly diagnosed cancer in females and the third most commonly diagnosed cancer in males worldwide (1). Patients with CRC have a poor prognosis due to cancer recurrence and metastasis following surgical resection. Numerous patients are at a high risk of recurrence and may be considered candidates

Correspondence to: Dr Xudong Wang, Center of Clinical Laboratory Medicine, Affiliated Hospital of Nantong University, 20 Xisi Road, Nantong, Jiangsu 226001, P.R. China

E-mail: wangxudong88@hotmail.com

Key words: growth-related oncogene- $\beta$, colorectal cancer, tissue microarray, immunohistochemistry, prognosis for targeted therapy or chemotherapy. However, colorectal carcinogenesis is a complicated process that is associated with cumulative genomic alterations $(2,3)$. Therefore, it is necessary to explore the molecular markers that underlie tumor progression and identify novel targets to improve therapeutic strategies and extend the survival of CRC patients.

Chemokines are a group of small proinflammatory cytokines that attract, activate and regulate leukocytes in inflamed tissues, and recent studies identified the role of chemokines in the initiation and promotion of carcinogenesis (3). Chemokines may be classified into three subfamilies, consisting of $\mathrm{C}, \mathrm{CC}$ and $\mathrm{CXC}$, on the basis of the number and arrangement of conserved cysteine residues. Growth-related oncogene (GRO) is a member of the CXC chemokine family, which is composed of GRO- $\alpha$, GRO- $\beta$, and GRO- $\gamma$, also termed the CXCL1, CXCL2 and CXCL3 genes, respectively (4,5). The chemokines have a conserved $\mathrm{CXC}$ motif at the $\mathrm{NH}_{2}$ terminus, but vary at the $\mathrm{COOH}$ terminus. The three GRO chemokines vary in binding affinity to CXCR2 or CXCR1 receptors, with GRO- $\alpha$ having the highest affinity with CXCR2 (6). GRO- $\alpha$ and GRO- $\beta$ have been identified to be dysregulated in pre-malignant colonic adenomas (7). However, the impact of GRO- $\beta$ overexpression on the clinical outcome in patients with CRC remains unclear. The present study explored the expression of GRO- $\beta$ in human CRC compared with adjacent normal tissue using cDNA microarray data and tissue microarray (TMA) sections, and assessed the potential correlation with the critical clinicopathological features of CRC and patient prognosis.

\section{Materials and methods}

cDNA microarray data. CXCL2 mRNA expression data were extracted from six independent studies and the expression levels in CRC tissues were compared with matched normal tissues using publicly available gene expression data in the Oncomine Cancer Microarray database (http://www.oncomine.org). All data were log-transformed and median-centered per array, and the standard deviation was normalized to one per array $(8,9)$.

Patients and samples. Formalin-fixed, paraffin-embedded tumor tissues and corresponding tumor-adjacent specimens were obtained during surgery from 198 patients with CRC treated at the Affiliated Hospital of Nantong University 
A
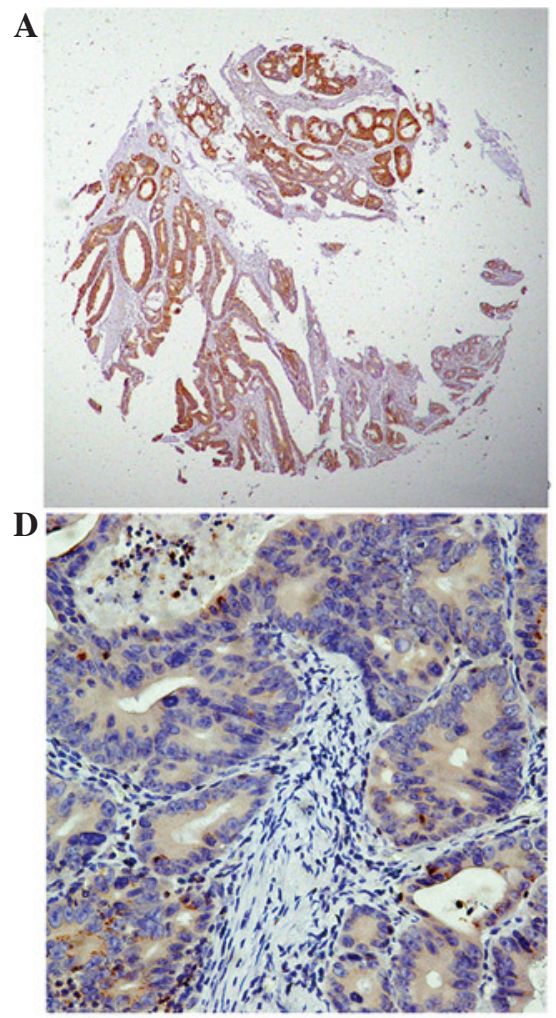

B

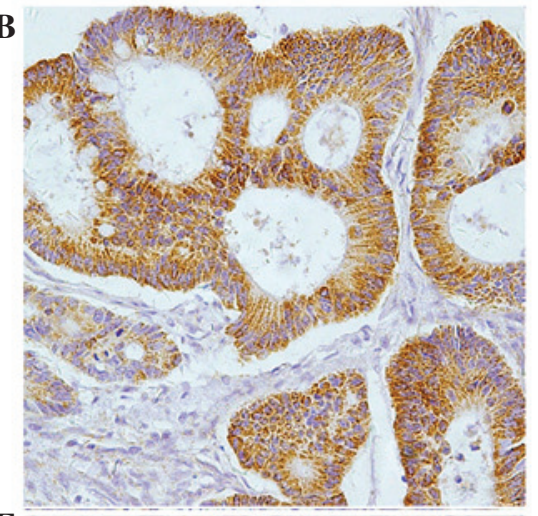

$\mathbf{E}$

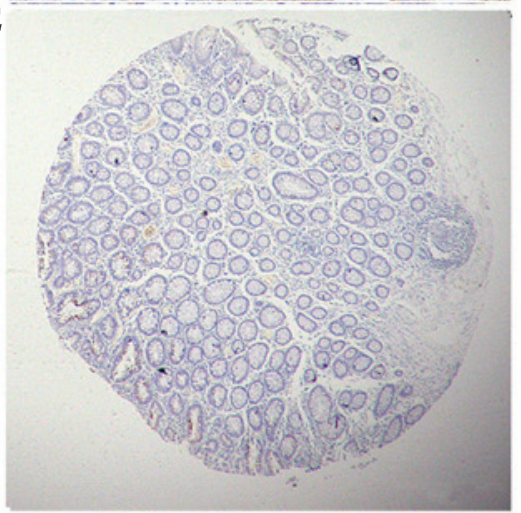

C

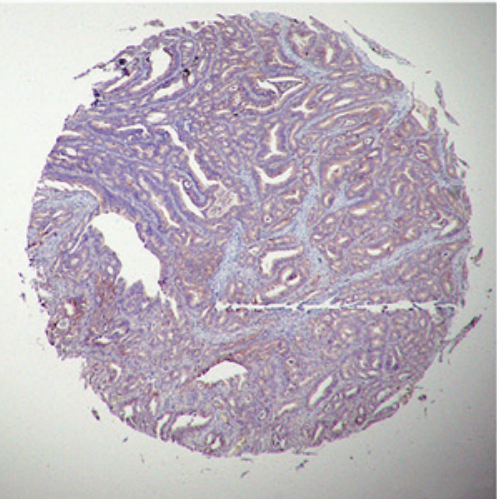

$\mathbf{F}$

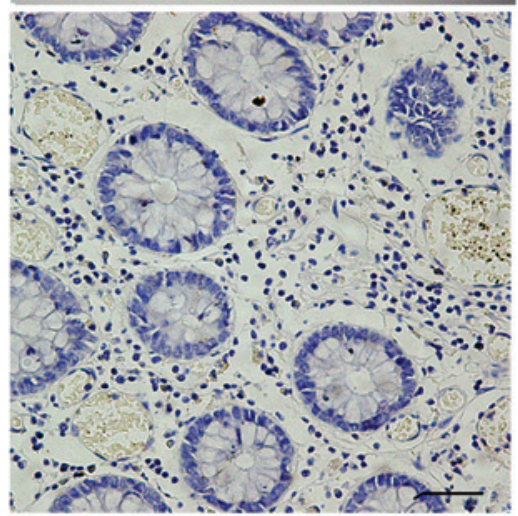

Figure 1. Various immunohistochemical staining patterns for GRO- $\beta$ in CRC and peritumoral tissues. The GRO- $\beta$ protein was highly expressed in the CRC tissue of a stage IIIB carcinoma; original magnification, (A) x40 and (B) $\times 400$. Low GRO- $\beta$ protein expression was observed in the CRC tissue of a stage IIA carcinoma; original magnification, (C) $\times 40$ and (D) $\times 400$. The expression of GRO- $\beta$ protein was negative in the adjacent normal peritumoral tissue; original magnification, (E) x40 and (F) x400. Scale bar, $50 \mu \mathrm{m}$. GRO- $\beta$, growth-related oncogene- $\beta$; CRC, colorectal cancer.

between 2002 and 2008. The clinical data, including gender, age, differentiation, location, extent of primary tumor, tumor-node-metastasis (TNM) classification, lymph node metastasis status, carcinoembryonic antigen (CEA) level and follow-up, including the 5-year survival rate, were obtained from the medical records of individual patients. The overall survival time was calculated as the time between the date of surgery and the date of mortality or last follow-up. The tumor stage was in accordance with the Union for International Cancer Control TNM system, but differentiation was determined following the World Health Organization standards (10). Representative $2.0-\mathrm{mm}$ tissue cores from each patient were used to conduct a tissue microarray (TMA) analysis using the Manual Tissue Microarrayer (Quick-Ray WI-UT06; Unitma Co., Ltd., Seoul, Korea).

Ethics statement. The present study was performed according to the principles expressed in the Declaration of Helsinki (11). Tissue specimens were collected with full written informed consent of the patients or the patients' families, in compliance with the institutional guidelines set by the Human Research Ethics Committee of the Affiliated Hospital of Nantong University. Ethical approval for the present study was granted by the Ethics Committee of the Affiliated Hospital of Nantong University (approval no., 2013-009).

Immunohistochemistry. For the immunohistochemical (IHC) analysis, TMA sections were deparaffinized in $100 \%$ xylene (Beyotime Institute of Biotechnology, Shanghai, China) and rehydrated in graded ethanol solutions (80, 95 and 100\%; Beyotime Institute of Biotechnology). Antigen retrieval was performed by boiling the sections under pressure $(90 \mathrm{kPa})$ in citrate buffer ( $\mathrm{pH}$ 6.0; Beyotime Institute of Biotechnology) for $5 \mathrm{~min}$. The non-specific binding site was blocked by incubating the sections in 5\% goat serum and phosphate buffered saline (PBS; Beyotime Institute of Biotechnology) for $15 \mathrm{~min}$. The TMA sections were incubated with a primary polyclonal rabbit anti-human GRO- $\beta$ antibody (dilution, 1:400; catalog no., 500-P104; PeproTech, Inc., Rocky Hill, NJ, USA) and subsequently with goat anti-rabbit horseradish peroxidase-conjugated antibody (dilution, 1:1,000; catalog no., sc-2004; Santa Cruz Biotechnology, Inc., Dallas, TX, USA). GRO- $\beta$ immunostaining underwent two independent evaluations under blind experimental conditions. The percentage of GRO- $\beta$-positive cells was recorded as $0-100 \%$, and the staining intensity was graded as follows: 0 , no staining; 1 , mild intensity; 2 , moderate intensity; and 3 , strong intensity. The final GRO- $\beta$ staining score was a product of the intensity grading and percentage of positive cells.

The threshold for the statistically significant GRO- $\beta$ expression scores in terms of overall survival (OS) time was set using the X-tile software program (http://www.tissuearray.org/rimmlab; Rimm Lab, Yale University, New Haven, CT, USA), as previously described (12). The degree of staining was quantified using a two-level grading system and the final GRO- $\beta$ staining score was defined as follows: 0-150, low expression; $150-300$, high expression. The typical expression patterns of GRO- $\beta$ are illustrated in Fig. 1. 

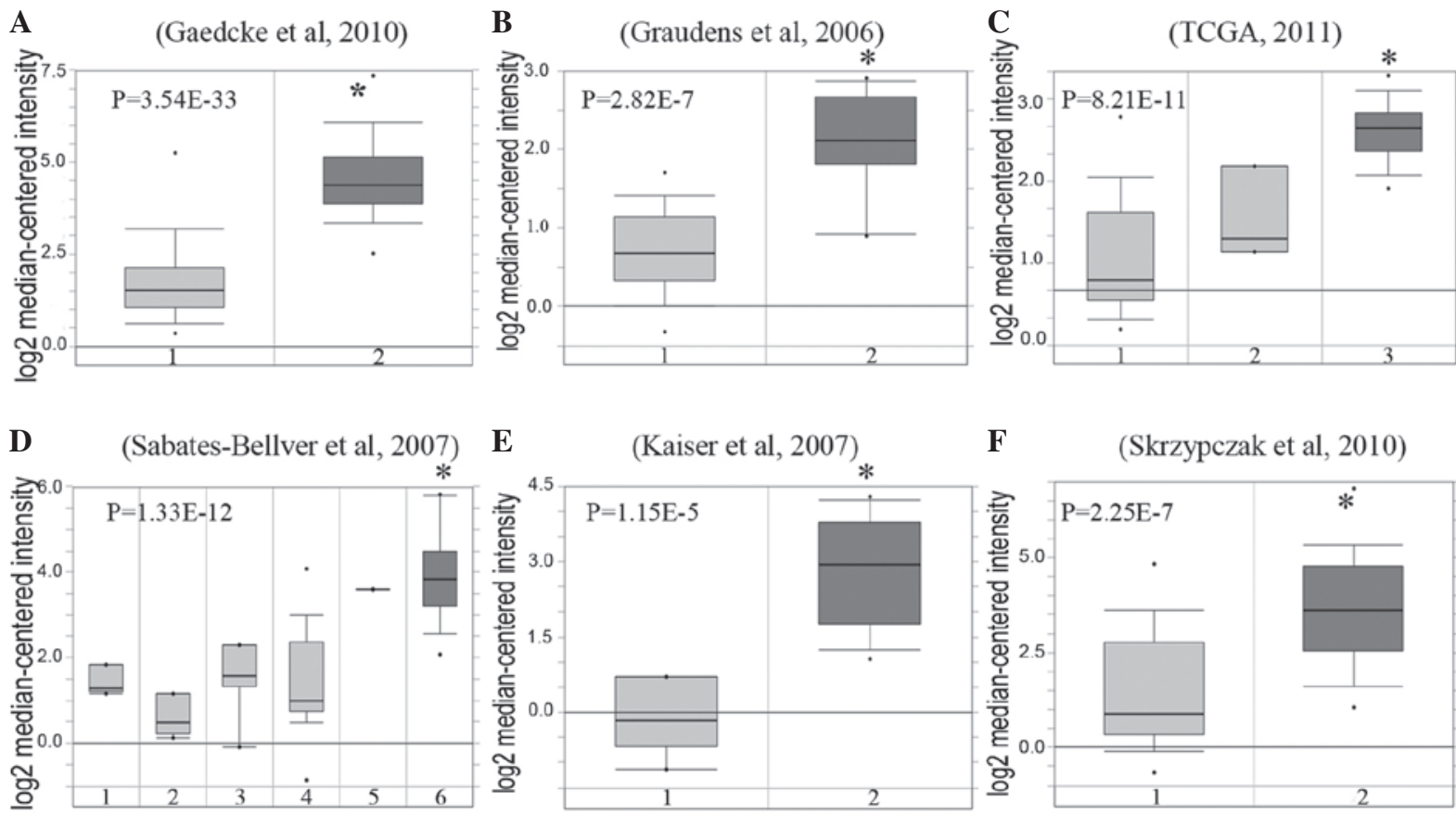

Figure 2. GRO- $\beta$ mRNA is overexpressed in colorectal cancer. GRO- $\beta$ expression in colorectal cancer tissues and normal tissues. Data sets in a single panel were from the same study. GEP data are log transformed and normalized. (A) Gaedcke et al (16): 1, 65 rectum samples; 2, 65 rectal adenocarcinoma samples. (B) Graudens et al (13): 1, 12 colon samples; 2, 18 colorectal carcinoma samples. (C) TCGA (18): 1, 19 colon samples; 2,3 rectum samples; 3 22 colon mucinous adenocarcinoma samples. (D) Sabates-Bellver et al (15): 1, 4 ascending colon samples; 2, 5 descending colon samples; 3,7 rectum samples; 4, 15 sigmoid colon samples; 5, 1 transverse colon sample; 6, 25 colon adenoma samples. (E) Kaiser et al (14): 1, 5 colon samples; 2, 17 cecum adenocarcinoma samples. (F) Skrzypczak et al (17): 1, 24 colorectal tissues samples; 2, 45 colorectal adenocarcinoma samples. GRO- $\beta$, growth-related oncogene- $\beta$; GEP, gene expression profiling. ${ }^{*} \mathrm{P}<0.05$.

Statistical analysis. SPSS version 20.0 software (IBM Corporation, Armonk, NY, USA) was used to conduct the statistical analyses. The comparison between the CXCL2 mRNA levels in the microarray was performed using the Mann-Whitney $\mathrm{U}$ or Student's $t$-tests. A $\chi^{2}$ test was used to analyze the association between GRO- $\beta$ expression and clinicopathological parameters, based on the IHC analysis. For the TMA slides, the gender, age, differentiation, location, extent of primary tumor, TNM classification, lymph node metastasis status and CEA level were assessed. The survival rate was calculated using the Kaplan-Meier method and Cox proportional hazards regression model, and the statistical differences were examined using the log-rank test. $\mathrm{P}<0.05$ was considered to indicate a statistically significant difference. All statistical tests were two-sided.

\section{Results}

CXCL2 mRNA is overexpressed in CRC. Using the Oncomine microarray database, the expression levels of CXCL2 mRNA in CRC tissues were increased compared with normal tissues from six independent studies (13-18). There was a significant difference between tumor tissue and normal tissue according to the mean expression value $(\mathrm{P}<0.0001$ in all six datasets; Fig. 2).

Expression of GRO- $\beta$ in CRC and peritumoral tissues, determined by IHC analysis. In order to investigate the expression of GRO- $\beta$ protein in colorectal carcinoma and the corresponding adjacent tissues, an IHC analysis on the primary colorectal tumors and normal colorectal mucosa was performed. As shown in Fig. 1, GRO- $\beta$ staining was detected at various levels, primarily in the cytoplasm of CRC cells. The staining index of cytoplasmic expression of GRO- $\beta$ in all 86 normal colorectal mucosa tissues was $<150$. High GRO- $\beta$ expression was detected in $31.31 \%(62 / 198)$ of CRC samples. Therefore, in accordance with the data of the CXCL2 mRNA analysis, the GRO- $\beta$ protein was confirmed to be highly expressed in CRC tissues.

Association between GRO- $\beta$ expression and clinicopathological features. The association between GRO- $\beta$ cytoplasmic expression and clinicopathological features of 198 cases of CRC was studied (Table I). The results revealed that high GRO- $\beta$ cytoplasmic expression in the primary CRC was significantly associated with the tumor location $(\mathrm{P}=0.022)$, extent of primary tumor $(\mathrm{P}=0.005)$ and lymph node metastasis $(\mathrm{P}=0.017)$. However, no significant association between GRO- $\beta$ levels and other clinicopathological characteristics, including patient gender, patient age, tumor differentiation, TNM stage and CEA level, were observed (Table I).

Prognostic value of high GRO- $\beta$ expression in CRC. In total, 68 patients succumbed during the postoperative follow-up period. The prognostic value of various factors was investigated using Kaplan-Meier analysis, and differentiation, TNM classification, extent of primary tumor, lymph node metastasis, CEA level and high GRO- $\beta$ expression were correlated with overall survival $(\mathrm{P}<0.05)$ (Table II). Kaplan-Meier survival curves demonstrated that patients with high GRO- $\beta$ expression possessed a significantly shorter survival time compared with 
Table I. Correlation of growth-related oncogene- $\beta$ expression in tumor tissues of colorectal cancer patients by clinicopathological characteristic.

\begin{tabular}{|c|c|c|c|c|c|}
\hline Characteristic & $\mathrm{N}$ & Low expression, n (\%) & High expression, n (\%) & Pearson $\chi^{2}$ & P-value \\
\hline Total & 198 & $136(68.69)$ & $62(31.31)$ & & \\
\hline \multicolumn{6}{|l|}{ Gender } \\
\hline Male & 126 & $86(68.25)$ & $40(31.75)$ & \multirow[t]{2}{*}{0.030} & \multirow[t]{2}{*}{0.862} \\
\hline Female & 72 & $50(69.44)$ & $22(30.56)$ & & \\
\hline \multicolumn{6}{|l|}{ Age, years } \\
\hline$<60$ & 65 & $45(69.23)$ & $20(30.77)$ & \multirow[t]{2}{*}{0.013} & \multirow[t]{2}{*}{0.908} \\
\hline$\geq 60$ & 133 & $91(68.42)$ & $42(31.58)$ & & \\
\hline \multicolumn{6}{|l|}{ Location } \\
\hline Colon & 145 & $93(64.14)$ & $52(35.86)$ & \multirow[t]{2}{*}{5.212} & \multirow[t]{2}{*}{$0.022^{\mathrm{a}}$} \\
\hline Rectum & 53 & $43(81.13)$ & $10(18.87)$ & & \\
\hline \multicolumn{6}{|l|}{ Differentiation } \\
\hline Well - middle & 166 & $113(68.07)$ & $53(31.93)$ & \multirow[t]{2}{*}{0.180} & \multirow[t]{2}{*}{0.671} \\
\hline Poor & 32 & $23(71.88)$ & $9(28.13)$ & & \\
\hline \multicolumn{6}{|l|}{ TNM stage } \\
\hline $\mathrm{I}$ & 46 & $38(82.61)$ & $8(17.39)$ & \multirow[t]{3}{*}{5.462} & \multirow[t]{3}{*}{0.065} \\
\hline II & 78 & $51(65.38)$ & $27(34.62)$ & & \\
\hline III+IV & 74 & $47(63.51)$ & $27(36.49)$ & & \\
\hline \multicolumn{6}{|l|}{$\mathrm{T}$} \\
\hline Tis $+1+2$ & 51 & $43(84.31)$ & $8(15.69)$ & \multirow[t]{2}{*}{7.799} & \multirow[t]{2}{*}{$0.005^{\mathrm{a}}$} \\
\hline $3+4$ & 147 & $93(63.27)$ & $54(36.73)$ & & \\
\hline \multicolumn{6}{|l|}{$\mathrm{N}$} \\
\hline 0 & 124 & 89 (71.77) & $35(28.23)$ & \multirow[t]{3}{*}{8.176} & \multirow[t]{3}{*}{$0.017^{\mathrm{a}}$} \\
\hline $1 a+1 b$ & 57 & $40(70.18)$ & $17(29.82)$ & & \\
\hline $2 a+2 b$ & 17 & $7(41.18)$ & $10(58.82)$ & & \\
\hline \multicolumn{6}{|l|}{ CEA } \\
\hline No & 119 & $81(68.07)$ & $38(31.93)$ & \multirow[t]{3}{*}{1.713} & \multirow[t]{3}{*}{0.191} \\
\hline Yes & 24 & $13(54.17)$ & $11(45.83)$ & & \\
\hline Unknown & 55 & $42(76.36)$ & $13(23.64)$ & & \\
\hline
\end{tabular}

${ }^{\mathrm{a}} \mathrm{P}<0.05$. TNM, tumor-node-metastasis; $\mathrm{T}$, size of the primary tumor; Tis, carcinoma in situ; $\mathrm{N}$, degree of spread to lymph nodes; CEA, carcinoembryonic antigen.

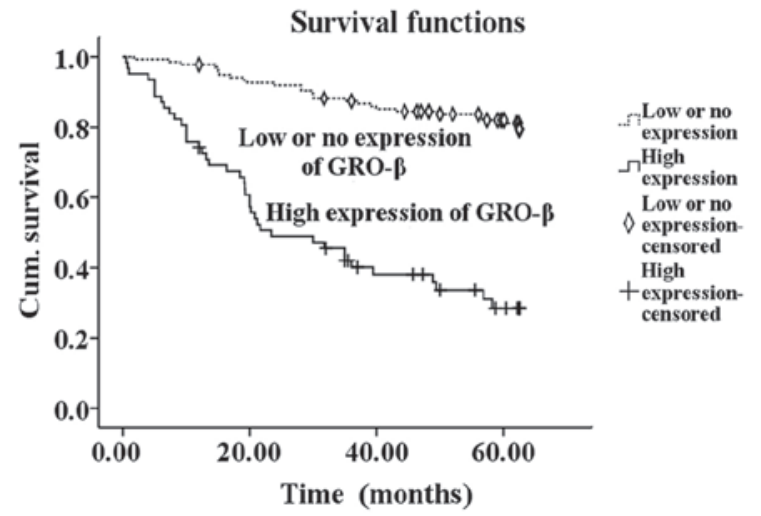

Figure 3. Kaplan-Meier survival curves of colorectal cancer patients with high and low GRO- $\beta$ expression. GRO- $\beta$, growth-related oncogene- $\beta$; Cum., cumulative.

the low GRO- $\beta$ expression group $(\mathrm{P}<0.001)$ (Fig. 3). In the additional multivariate Cox regression analyses, subsequent to adjustment for gender, age, location, differentiation, tumor stage and lymph node metastasis, high GRO- $\beta$ expression $(\mathrm{P}<0.001)$, TNM classification $(\mathrm{P}=0.002)$ and $\mathrm{CEA}$ level $(\mathrm{P}=0.027)$ remained as independent predictive factors of a poor outcome in CRC (Table III). Overall, the results indicate that high GRO- $\beta$ expression may act as a prognostic marker for CRC.

\section{Discussion}

Previously, the potential oncogenic role of GRO- $\beta$ in the promotion of several human cancers has been examined, including in esophageal squamous cell carcinoma and melanoma $(19,20)$. Little is understood regarding the role of GRO- $\beta$ in CRC. To the best of our knowledge, only two studies have investigated the potential role of GRO- $\beta$ in colorectal tumors at present. These studies indicated that the expression of CXCL2 mRNA was significantly increased in CRC compared with normal colon tissue using quantitative reverse transcription-polymerase chain reaction (6) and that CXCL2 mRNA was also enhanced in premalignant adenomas in a previous small cohort study (7), which suggests that the dysregulation of GRO- $\beta$ may be an early event in the tumorigenesis of CRC. Additional statistical 
Table II. Kaplan-Meier univariate analysis of the overall survival time of colorectal cancer patients following surgery.

\begin{tabular}{|c|c|c|c|}
\hline \multirow[b]{2}{*}{ Variable } & \multicolumn{3}{|c|}{ Univariate analysis } \\
\hline & Survival in months \pm standard error & $95 \%$ confidence interval & P-value \\
\hline \multicolumn{4}{|c|}{ GRO- $\beta$ expression } \\
\hline Low & $56.24 \pm 1.29$ & $53.71-58.77$ & \multirow[t]{2}{*}{$<0.001^{\mathrm{a}}$} \\
\hline High & $33.02 \pm 2.99$ & $27.16-38.88$ & \\
\hline \multicolumn{4}{|l|}{ Gender } \\
\hline Female & $51.68 \pm 2.35$ & $47.07-56.29$ & \multirow[t]{2}{*}{0.153} \\
\hline Male & $47.67 \pm 1.92$ & $43.91-51.42$ & \\
\hline \multicolumn{4}{|l|}{ Age, years } \\
\hline$<60$ & $48.97 \pm 2.64$ & $43.80-54.14$ & \multirow[t]{2}{*}{0.929} \\
\hline$\geq 60$ & $49.21 \pm 1.84$ & $45.61-52.81$ & \\
\hline \multicolumn{4}{|l|}{ Location } \\
\hline Rectum & $50.11 \pm 1.74$ & $46.70-53.52$ & \multirow[t]{2}{*}{0.169} \\
\hline Colon & $46.59 \pm 2.89$ & $40.92-52.27$ & \\
\hline \multicolumn{4}{|l|}{ Differentiation } \\
\hline Well - middle & $50.53 \pm 1.57$ & $47.45-53.61$ & \multirow[t]{2}{*}{$0.044^{\mathrm{a}}$} \\
\hline Poor & $41.70 \pm 4.18$ & $33.51-49.89$ & \\
\hline \multicolumn{4}{|l|}{ TNM stage } \\
\hline I & $59.73 \pm 1.55$ & $56.69-62.76$ & \multirow[t]{3}{*}{$<0.001^{\mathrm{a}}$} \\
\hline II & $49.46 \pm 2.30$ & $44.95-53.97$ & \\
\hline III +IV & $42.08 \pm 2.75$ & $36.68-47.48$ & \\
\hline \multicolumn{4}{|l|}{$\mathrm{T}$} \\
\hline Tis $+1+2$ & $59.36 \pm 1.52$ & $56.39-62.33$ & \multirow[t]{2}{*}{$<0.001^{\mathrm{a}}$} \\
\hline $3+4$ & $45.52 \pm 1.86$ & $41.88-49.17$ & \\
\hline \multicolumn{4}{|l|}{$\mathrm{N}$} \\
\hline 0 & $53.34 \pm 1.62$ & 50.18-56.51 & \multirow[t]{3}{*}{$<0.001^{\mathrm{a}}$} \\
\hline $1 \mathrm{a}+1 \mathrm{~b}$ & $45.46 \pm 3.14$ & $39.29-51.62$ & \\
\hline $2 a+2 b$ & $30.85 \pm 4.91$ & $21.22-40.47$ & \\
\hline \multicolumn{4}{|l|}{ CEA } \\
\hline No & $51.59 \pm 1.73$ & $48.20-54.98$ & \multirow[t]{2}{*}{$0.001^{\mathrm{a}}$} \\
\hline Yes & $38.13 \pm 5.12$ & $28.10-48.15$ & \\
\hline
\end{tabular}

${ }^{\mathrm{a}} \mathrm{P}<0.05$. GRO- $\beta$, growth-related oncogene- $\beta$; TNM, tumor-node-metastasis; $\mathrm{T}$, size of the primary tumor; Tis, carcinoma in situ; $\mathrm{N}$, degree of spread to lymph nodes; CEA, carcinoembryonic antigen.

Table III. Results of the Cox multivariate regression analysis of the overall survival of colorectal cancer patients.

\begin{tabular}{lcccccc}
\hline Factor & $\beta$ & $\mathrm{SE}(\beta)$ & Wald & P-value & $\mathrm{e}^{\beta}$ hazard ratio & 95.0\% CI for $\mathrm{e}^{\beta}$ hazard ratio \\
\hline GRO- $\beta$ & 1.778 & 0.306 & 33.702 & 0.000 & 5.920 & $3.248-10.791$ \\
TNM & 0.653 & 0.222 & 8.613 & 0.003 & 1.921 & $1.242-2.970$ \\
CEA & 0.758 & 0.325 & 5.461 & 0.019 & 2.135 & $1.130-4.032$ \\
\hline
\end{tabular}

Degrees of freedom $=1$ (for all factors). GRO- $\beta$, growth-related oncogene- $\beta$; TNM, tumor-node-metastasis; CEA, carcinoembryonic antigen; $\beta$, regression coefficient; $\operatorname{SE}(\beta)$, standard error of the regression coefficient; Wald, Wald test score; $\mathrm{e}^{\beta}$ hazard ratio, relationship between treatment effect and hazard ratio; $\mathrm{CI}$, confidence interval.

analyses revealed that CXCL2 mRNA was overexpressed in malignant colorectal tissues compared with normal adjacent tissues using microarray data from six independent datasets (13-18).

The present study explored the expression of the GRO- $\beta$ protein in human CRC compared with adjacent tissues, and assessed the potential correlation with the critical clinicopathological features of CRC and the patient outcome. Several notable observations were made from the results.

First, the GRO- $\beta$ protein was demonstrated to be highly expressed in a series of $198 \mathrm{CRCs}$ comprising all stages of disease using an IHC approach. In addition, overexpression was 
found to be associated with neoplastic epithelial cells rather than inflammatory cells or non-epithelial stroma. Notably, the division of the data into two categories according to localization indicated that increased GRO- $\beta$ expression in the colon was significantly more frequent compared with the rectum $(\mathrm{P}=0.022)$. Previously, cancers of the rectum and colon have been implicated as distinct tumors, as they have a dissimilar prevalence and variations in the clinical presentation, prognosis and possibly genetic and environmental epidemiology $(21,22)$. Therefore, GRO- $\beta$ expression may affect carcinogenesis of the colorectal tissues in a site-specific manner. The findings of the present study provide additional evidence that colon and rectal cancers possessed varied etiologies. In addition, GRO- $\beta$ expression was significantly associated with the extent of the primary tumor and lymph node metastasis. Increased GRO- $\beta$ expression is associated with a more advanced stage of disease and the propensity to develop lymph node metastasis. These results suggest that the overexpression of cytoplasmic GRO- $\beta$ in CRC may facilitate cancer cell invasion and metastasis. Previous studies have also reported that the increased expression of GRO- $\beta$ was involved in the development and invasion of several types of carcinomas, including esophageal squamous cell carcinoma (19) and melanoma (20). The data in the present study clearly revealed that a high cytoplasmic expression of GRO- $\beta$ was associated with significantly poorer survival time. Multivariate analyses revealed that GRO- $\beta$ expression was regarded as an independent prognostic factor for CRC patients. In addition to increased GRO- $\beta$ expression, TNM classification and high CEA levels are also considered to be independent factors for a poor prognosis in CRC. Overall, GRO- $\beta$ expression may be an important prognostic factor for aggressive human CRC. GRO- $\beta$ has potential value as a therapeutic target in patients with CRC.

In conclusion, the role of GRO- $\beta$ in the pathophysiology of CRC carcinogenesis and progression is unclear. GRO- $\beta$ is a classical neutrophil chemoattractant and was the first chemokine to be identified as a product of neutrophils, and to be demonstrated to mediate neutrophil recruitment, the release of granule enzymes and the expression of adhesion molecules, which multiply inflammatory effects (7). Chronic inflammation may increase the risk of cancer development $(23,24)$. GRO- $\beta$ is excessively expressed during inflammation and is chemotactic for neutrophils in combination with the CXCR2 receptor. GRO- $\beta$ is crucial in the initiation and progression of colitis-associated colon cancer, and the GRO- $\beta$-CXCR2 axis may be useful in decreasing the risk of ulcerative colitis-associated colon cancer $(6,7)$. Sufficient evidence demonstrates that chemokines are also significant in cancer, in addition to having a role in the development and inflammatory responses $(25,26)$. GRO increases matrix metalloproteinase production in oral squamous cell carcinoma by binding to CXCR2, which may participate in cancer progression (26). Wang et al (27) also indicated that GRO- $\beta / C X C R 2$ forms an autocrine loop by activating the ERK1/2 pathway, and contributes significantly to proliferation in primary esophageal squamous cell carcinoma.

The findings of the present study suggest that GRO- $\beta$ was overexpressed in the cytoplasm of CRC cells rather than inflammatory cells. However, the association between GRO- $\beta$ protein expression and the clinical characteristics of CRC was confined to clinical observations using a tumor tissue microarray. The association between GRO- $\beta$ in colorectal carcinogenesis and the autocrine or paracrine mechanisms and the signal pathways involved remains to be elucidated. Additional in vitro and in vivo studies are required in order to investigate the biological functions of GRO- $\beta$ in CRC.

\section{Acknowledgements}

This study was supported by grants from the Translational Medicine Program of Affiliated Hospital of Nantong University (grant no. TDFzh2014014), the Six Talent Peaks Program of Jiangsu Province (grant no. 2012-ws-064) and the 226 Talent Training Project of Nantong City (The Fourth Batch).

\section{References}

1. Siegel R, Naishadham D and Jemal A: Cancer statistics, 2013. CA Cancer J Clin 63: 11-30, 2013.

2. Rao CV and Yamada HY: Genomic instability and colon carcinogenesis: From the perspective of genes. Front Oncol 3: 130, 2013

3. Khan S, Cameron S, Blaschke M, Moriconi F, Naz N, Amanzada A, Ramadori G and Malik IA: Differential gene expression of chemokines in KRAS and BRAF mutated colorectal cell lines: Role of cytokines. World J Gastroenterol 20: 2979-2994, 2014

4. Modi WS and Yoshimura T: Isolation of novel GRO genes and a phylogenetic analysis of the CXC chemokine subfamily in mammals. Mol Biol Evol 16: 180-193, 1999.

5. Wang D and Richmond A: Nuclear factor-kappa B activation by the CXC chemokine melanoma growth-stimulatory activity/growth-regulated protein involves the MEKK1/p38 mitogen-activated protein kinase pathway. J Biol Chem 276: 3650-3659, 2001.

6. Doll D, Keller L, Maak M, Boulesteix AL, Siewert JR, Holzmann B and Janssen KP: Differential expression of the chemokines GRO-2, GRO-3, and interleukin-8 in colon cancer and their impact on metastatic disease and survival. Int J Colorectal Dis 25: 573-581, 2010.

7. McLean MH, Murray GI, Stewart KN, Norrie G, Mayer C, Hold GL, Thomson J, Fyfe N, Hope M, Mowat NA, et al: The inflammatory microenvironment in colorectal neoplasia. PLoS One 6: e15366, 2011.

8. Rhodes DR, Yu J, Shanker K, Deshpande N, Varambally R, Ghosh D, Barrette T, Pandey A and Chinnaiyan AM: Large-scale meta-analysis of cancer microarray data identifies common transcriptional profiles of neoplastic transformation and progression. Proc Natl Acad Sci USA 101: 9309-9314, 2004.

9. Rhodes DR, Yu J, Shanker K, Deshpande N, Varambally R, Ghosh D, Barrette T, Pandey A and Chinnaiyan AM: ONCOMINE: A cancer microarray database and integrated data-mining platform. Neoplasia 6: 1-6, 2004.

10. Ueno H, Mochizuki H, Akagi Y, Kusumi T, Yamada K, Ikegami M, Kawachi H, Kameoka S, Ohkura Y, Masaki T, et al: Optimal colorectal cancer staging criteria in TNM classification. J Clin Oncol 30: 1519-1526, 2012.

11. Williams JR: The Declaration of Helsinki and public health. Bull World Health Organ 86: 650-652, 2008

12. Sun R, Wang X, Zhu H, Mei H, Wang W, Zhang S and Huang J: Prognostic value of LAMP3 and TP53 overexpression in benign and malignant gastrointestinal tissues. Oncotarget 5: 12398-12409, 2014.

13. Graudens E, Boulanger V, Mollard C, Mariage-Samson R, Barlet X, Grémy G, Couillault C, Lajémi M, Piatier-Tonneau D, Zaborski P, et al: Deciphering cellular states of innate tumor drug responses. Genome Biol 7: R19, 2006.

14. Kaiser S, Park YK, Franklin JL, Halberg RB, Yu M, Jessen WJ, Freudenberg J, Chen X, Haigis K, Jegga AG, et al: Transcriptional recapitulation and subversion of embryonic colon development by mouse colon tumor models and human colon cancer. Genome Biol 8: R131, 2007.

15. Sabates-Bellver J, Van der Flier LG, de Palo M, Cattaneo E, Maake C, Rehrauer H, Laczko E, Kurowski MA, Bujnicki JM, Menigatti M, et al: Transcriptome profile of human colorectal adenomas. Mol Cancer Res 5: 1263-1275, 2007. 
16. Gaedcke J, Grade M, Jung K, Camps J, Jo P, Emons G, Gehoff A, Sax U, Schirmer M, Becker H, et al: Mutated KRAS results in overexpression of DUSP4, a MAP-kinase phosphatase, and SMYD3, a histone methyltransferase, in rectal carcinomas. Genes Chromosomes Cancer 49: 1024-1034, 2010.

17. Skrzypczak M, Goryca K, Rubel T, Paziewska A, Mikula M, Jarosz D, Pachlewski J, Oledzki J and Ostrowski J: Modeling oncogenic signaling in colon tumors by multidirectional analyses of microarray data directed for maximization of analytical reliability. PLoS One 5: e13091, 2010.

18. Cancer Genome Atlas Network: Comprehensive molecular characterization of human colon and rectal cancer. Nature 487: 330-337, 2012.

19. Dong QM, Zhang JQ, Li Q, Bracher JC, Hendricks DT and Zhao XH: Clinical significance of serum expression of GRO $\beta$ in esophageal squamous cell carcinoma. World J Gastroenterol 17: 2658-2662, 2011.

20. Owen JD, Strieter R, Burdick M, Haghnegahdar H, Nanney L, Shattuck-Brandt R and Richmond A: Enhanced tumor-forming capacity for immortalized melanocytes expressing melanoma growth stimulatory activity/growth-regulated cytokine beta and gamma proteins. Int J Cancer 73: 94-103, 1997.

21. Buhmeida A, Bendardaf R, Hilska M, Laine J, Collan Y, Laato M, Syrjänen K and Pyrhönen S: PLA2 (group IIA phospholipase A2) as a prognostic determinant in stage II colorectal carcinoma. Ann Oncol 20: 1230-1235, 2009.
22. Saif MW and Chu E: Biology of colorectal cancer. Cancer J 16: 196-201, 2010.

23. Inoue Y, Iwata T, Okugawa Y, Kawamoto A, Hiro J, Toiyama Y, Tanaka K, Uchida K, Mohri Y, Miki C and Kusunoki M: Prognostic significance of a systemic inflammatory response in patients undergoing multimodality therapy for advanced colorectal cancer. Oncology 84: 100-107, 2013.

24. Ishizuka M, Nagata H, Takagi K, Iwasaki Y and Kubota K: Inflammation-based prognostic system predicts survival after surgery for stage IV colorectal cancer. Am J Surg 205: 22-28, 2013.

25. Dorhoi A, Iannaccone M, Farinacci M, Faé KC, Schreiber J, Moura-Alves P, Nouailles G, Mollenkopf HJ, Oberbeck-Müller D, Jörg S, et al: MicroRNA-223 controls susceptibility to tuberculosis by regulating lung neutrophil recruitment. J Clin Invest 123: 4836-4848, 2013.

26. Shang K, Bai YP, Wang C, Wang Z, Gu HY, Du X, Zhou XY, Zheng CL, Chi YY, Mukaida N and Li YY: Crucial involvement of tumor-associated neutrophils in the regulation of chronic colitis-associated carcinogenesis in mice. PLoS One 7: e51848, 2012.

27. Wang B, Khachigian LM, Esau L, Birrer MJ, Zhao X, Parker MI and Hendricks DT: A key role for early growth response-1 and nuclear factor-kappaB in mediating and maintaining GRO/CXCR2 proliferative signaling in esophageal cancer. Mol Cancer Res 7: 755-764, 2009. 